\title{
MÃE MODERNA: ESPORTIVA E FORTE
}

\author{
Maria Simone Vione Schwengber ${ }^{*}$
}

RESUMO: O presente artigo é parte de uma pesquisa inspirada nos campos dos estudos de gênero, que se aproximam das teorizações de Michel Foucault. Nele, discuto a emergência de uma lógica, segundo a qual a educação dos corpos, de modo geral, e o das mulheres, de forma específica, se intensifica a partir do século XVIII. Temos definido esse processo educativo contemporâneo mais amplo como "politização do feminino e da maternidade" (Meyer, 2003); um processo que, por extensão, inclui a "politização do corpo grávido" (Schwengber, 2006). Para essa discussão, examinei a revista Pais \& Filhos, no período de 1968 a 2004, utilizando-me das estratégias metodológicas da análise de discurso. Do resultado das análises, focalizo um movimento que permite visualizar a emergência de uma lógica, segundo a qual a educação dos corpos grávidos se intensifica por meio das práticas corporais, construindo diferentes posições de sujeito: a de mãe preparada (que cuida e se cuida), esportiva e sensual; responsável pelo corpo perfeito.

Palavras-chave: Corpo. Gênero. Práticas corporais. Maternidade. Mídia.

\section{MODERN MOTHER: SPORTING AND STRONG}

ABSTRACT: The present research discussed some of the ways that different discourses, from medicine to physical education, have invested on the pregnant body. To carry out this discussion, I have examined the Pais \& Filhos magazine, published from 1968 to 2004, using methodological strategies of discourse analysis. I have attempted to show that alternative, sports and fitness body practices

Doutora em Educação e professora do Curso de Educação Física e do Mestrado em Educação nas Ciências da Universidade Regional do Noroeste do Estado do Rio Grande do Sul (Unijuí).E-mail: simone@unijui.edu.br 
in the magazine have been constituted as an important elements of a "self-care" discourse, mainly when they produce different positions of a caring mother-subject (that one that takes care of others and of herself), prepared, athletic, strong.

Key words: Pregnant body. Gender. Body practices. Motherhood. Media.

\section{Politização da maternidade contemporânea}

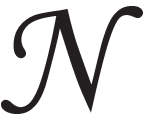

a contemporaneidade, observa-se a emergência de uma rede mais ampla de cuidados e de novos saberes acerca dos corpos, sobretudo, dos corpos grávidos. Uma rede de saberes - de áreas como obstetrícia, enfermagem, fisioterapia, nutrição, psicologia, psicanálise, educação física, religião, economia e direito - passa a ser destacada como fundamental a um bom pré-natal. Assim, o processo de condução da gravidez tornou-se progressivamente "ativo e intervencionista", como diz Forna ${ }^{1}$ (1999, p. 45).

Do ponto de vista de Forna (op. cit.), o que se acentua, no contexto atual, é a exaltação da vida intraútero, a ideia de que uma vida saudável nasce no ventre de uma mulher. Proliferam as publicações que afirmam ser no primeiro período - o gestacional, no útero - que o trajeto de saúde do indivíduo se define. Parece que se expande, com mais força, a partir daí, a concepção de que a nossa saúde é administrada e gerenciada "desde o embrião até o leito de morte", como destaca Dagmar Meyer (2004).

Esses pressupostos foram (e têm sido) os principais instrumentos usados para marcar uma nova representação de mulher-mãe e de seu envolvimento na gravidez, no parto e na criação do(a)s filho(a)s. Assim, entendo (junto com outras estudiosas feministas) que esses pressupostos abriram espaços para, entre outras coisas, fixar a exclusividade da mãe, não só no processo reprodutivo estrito senso, mas, também, em outras dimensões da reprodução social da vida humana, tal como a educação, o cuidado e a criação do(a)s filho(a)s (Meyer, op. cit.; Ana Paula Vosne Martins, 2004).

Elisabeth Badinter (2003) destaca que a sociedade ocidental contemporânea promove uma individualização da maternidade, a figura da 
mãe responsável, tanto pelas práticas - saúde, puericultura, ${ }^{2}$ educação na infância - quanto pela simbologia, com o crescimento do sentimento maternal, sendo a mãe aquela que dá "o amor a mais", a vida, o alimento e as primeiras e contínuas socializações.

Entendo que esses pressupostos estão na base de um movimento hodierno mais amplo, que chamamos de nova politização do corpo grávido, como diz Meyer (2004, p. 1): “(...) nova não no sentido de inovadora, mas no sentido de uma atualização, exacerbação, complexificação e multiplicação de investimentos educativo-assistenciais" e amorosos. A educação dos corpos grávidos na atualidade reinscreve o corpo da mulher-mãe em um rigoroso regime de vigilância e de regulação, ${ }^{3}$ uma tarefa cada vez mais complexa e de muitas aprendizagens e exigências.

Assim, interessei-me pela problemática da politização da maternidade e, em particular, pela politização dos corpos grávidos, no contexto de um artefato específico da mídia impressa brasileira, a revista Pais \& Filhos. Rosa Maria Bueno Fischer (2002) é uma das estudiosas que chama a atenção para a importância que a mídia assume, ocupando uma posição central no processo de constituição do sujeito contemporâneo, nos modos de ser homem e mulher, inclusive nos modos de ser pai, mãe e gestante.

Seduziu-me o desafio de responder à seguinte pergunta: Como o discurso das práticas corporais e esportivas, na Pais \& Filhos, colabora com o processo dessa politização?. Nesse sentido, este artigo assume o desafio de descrever e analisar como algumas das qualidades físicas foram (e são), historicamente, colocadas em cena por determinadas pedagogias corporais para produzirem identidades maternas diferenciadas.

Para respondê-las, examinei exemplares da revista Pais \& Filhos, ${ }^{4}$ apoiando-nos na perspectiva dos estudos de gênero. Como estratégia metodológica, utilizei a análise de discurso foucaultiana. Do ponto de vista da metodologia adotada, realizei as análises valendo-me das contribuiçôes de Foucault no que tange ao conceito de discurso e enunciado. Ele sugere que o(a) pesquisador(a) tome os discursos, em sua materialidade, e tencione suas condições de produção e as posições de sujeito neles descritas.

Instrumentalizada por esse modo de ver, optei por mapear os enunciados nos discursos da Pais \& Filhos, partindo das observações de 
regularidades, insistências e repetiçôes. Assim, analisei os discursos e as imagens que integram, frequentemente, os textos da revista, não como peças ilustrativas, mas como práticas discursivas. Carmen Soares (2000) e Silvana Vilodre Goellner (2004) ensinam que as imagens não são independentes, pois estão ligadas a determinados regimes de poder e movimentam significados, induzindo o(a) leitor(a) a visualizar (focalizar) certas coisas em detrimento de outras.

\section{A educação da mãe esportiva e forte}

A partir da primeira década de sua existência (1968-1978), a revista Pais \& Filhos apresenta uma rede mais ampla de cuidados, de novos saberes, que passam a ser destacados como fundamentais a um bom pré-natal. Como se vê, são muitos os discursos e as intervenções destinados a educar os corpos grávidos, de modo que as práticas corporais esportivas, como exemplo de práticas contemporâneas, não ficam fora dessa rede educativa. Na segunda edição da Pais \& Filhos, já encontrei a primeira prescrição de exercícios físicos para gestantes, traduzida nesta chamada:

Abaixo os Tabus da Gravidez... exercícios na gravidez.

Exercícios físicos, sim. (Pais \& Filhos, v. 1, n. 2, p. 66, out. 1968)

A Pais \& Filhos faz, inicialmente, um claro esforço para combater os ditos tabus, afirmando que os exercícios físicos "não são proibidos, nem perigosos, nem considerados impuros". Essa chamada traz junto uma imagem de corpo com roupa esportiva, cabelos curtos, olhos marcados pela maquiagem (ou seja, toalete sofisticada, mesmo que esportiva), aspectos visuais que colaboram para indicar os traços modernos e fortes da gestante. Era impensável, no contexto em que emergia a revista (no ano de 1968), aspirar ser moderna: sem cortar o cabelo, sem recorrer à maquiagem, ao uso de roupas e a práticas esportivas. A publicação investe na produção da nova mulher: moderna, uma mãe com iniciativa, ágil e capaz de enfrentar os desafios, inclusive superar alguns tabus, entre os quais a ideia do desprezo do exercício físico para grávidas.

Avançando um pouco mais, Schpun (1999) identificou no esporte um elemento da expressão da modernidade, inclusive associando-o à 
mulher. A literatura brasileira apresenta visões diversas dos indicativos da expansão das práticas esportivas para mulheres, no caso para as gestantes. Apesar disso, foi apenas a partir da década de 1930 (da aceleração da modernização social ocorrida) que tivemos evidências ${ }^{5}$ do aumento da prática esportiva feminina em nosso país, inclusive, para o contingente de mulheres grávidas (Goellner, 2003).

O século XX testemunhou uma ampla popularização do esporte, uma enorme penetrabilidade social. A capacidade de mobilização popular pelo esporte permitiu que fossem estabelecidas interfaces com dimensões da vida social que transitam desde a saúde até a economia e à política, passando pelos conflitos de ordem racial e étnica. No entanto, foi a partir das primeiras décadas do século XX que a participação das mulheres se ampliou, adquirindo, portanto, maior visibilidade, com o desenvolvimento industrial, as novas tecnologias, a urbanização, a mão de obra imigrante, o fortalecimento do Estado, as manifestaçōes operárias e os movimentos grevistas - sobretudo, o movimento feminista, cujas militantes lutaram pela experimentação de prazeres dos sentidos corporais e de novas possibilidades culturais.

Nessa perspectiva, as práticas corporais e esportivas se inserem de modo mais alargado no contexto social. As inúmeras articulações e os diálogos do esporte com outras esferas da vida materializam um pressuposto que me parece fundamental para uma reflexão acerca desse fenômeno: há uma profunda correspondência entre esporte e sociedade(s) (Dailo, 2004). Existe, consequentemente, uma inexorável ligação entre a maneira como as práticas corporais e esportivas se manifestam e os valores culturais da sociedade que as pratica.

Soares (2003) instiga-nos a considerar que, nos últimos duzentos anos, no mundo ocidental, tem-se afirmado/firmado "uma cultura do movimento", sustentada pela ciência e pela tecnologia, sobrepondo-se aos indivíduos, aos grupos, às diferentes classes sociais, como prática importante de cuidado que (re)define seus objetivos como "uma prática indispensável à saúde". ${ }^{6}$ Como bem observa a autora (2003, p. 10), parece que hoje há uma tentativa de convencimento "da necessidade imperiosa de colocar o corpo em movimento, sem o que não há saúde”.

Goellner (2004) destaca vários acontecimentos e movimentos que contribuíram para a afirmação da importância das práticas corporais e 
esportivas prescritas para as mulheres, inclusive para as gestantes, no século XX. Estes acontecimentos e circunstâncias ajudaram a reforçar a importância das práticas corporais e esportivas para mulheres, como competições nacionais e internacionais, Jogos Olímpicos, criação de clubes esportivos, programas governamentais e não governamentais, mulheres "que faziam força física em casas de espetáculos, circos e music halls nos Estados Unidos e Europa” (Goellner, op. cit., p. 362), proliferação das imagens esportivas da mídia nos cinemas e propagandas, a própria profissionalização do ideário esportivo, os concursos de misses, entre outros acontecimentos.

Entendo que eventos esportivos como os destacados por Goellner (op. cit.) criaram e criam condições de possibilidade para a afirmação, cada vez maior, da prescrição dessas práticas para as mulheres brasileiras, e também para as grávidas. São muitos os discursos e intervençôes destinados a educar os corpos grávidos; o esporte, como prática contemporânea, não fica distante dessa afirmação. Não é à toa que uma variedade dessas práticas para as gestantes eclodiu com mais força a partir da segunda metade do século XX, ${ }^{7}$ garantindo-se como hábito importante de cuidado, pautado pela negação do corpo real e pela busca de aprimoramento do corpo grávido e da saúde. A medida que os anos transcorre$\mathrm{ram}$, as perspectivas sob as quais se qualificavam as práticas corporais e esportivas para as gestantes foram se alterando, sendo possível identificar, nas últimas décadas, algumas mudanças importantes.

\section{Mãe forte é a mãe esportiva}

As gestantes, no contexto da Pais \& Filhos, são geralmente retratadas como mulheres que se preparam para o parto, aquelas que acompanham os métodos científicos que levam a sério seu corpo. Já não são mais tão tímidas, recatadas, mas mulheres ativas e fortes, mais próximas de si quando o assunto é o cuidado com o próprio corpo. De 1980 a 1990, parece haver um movimento que trabalha para fortalecer a representação de mulher forte, que demonstra firmeza e eficiência em quase todas as situações, como podemos observar em chamadas como as que seguem:

(...) Aprenda a virar o jogo - a ser forte. (Pais \& Filhos, 1978, capa)

(...) Você, mãe, é forte para segurar as pontas na administração da família. (Pais \& Filhos, 1980, p. 21) 
(...) Uma mãe forte malha todo dia para manter seu corpo em forma. (...) uma mãe forte constrói espaço para ter e para manter o corpo em forma no trabalho de parto. (Pais \& Filhos, 1988, p. 14)

Essas narrativas remetem à construção de gênero da mulher-fortefirme. Ser forte é uma qualidade positivada pela revista. Parece que, a partir da década de 1980, a Pais \& Filhos não nega, ao contrário, apela para o desenvolvimento da força física, enfatizando-a não apenas no sentido restrito da força como capacidade física, mas também em diversos sentidos, em termos de afetividade, de rendimento, de ser forte, de "segurar as pontas", enfim, de saber lidar com os contrapontos da vida.

As capacidades físicas de força muscular, do vigor físico, da resistência e da potência são vistas agora como importantes e necessárias tanto às identidades masculinas quanto às femininas, particularmente quando se trata de mulheres gestantes. Assim sendo, a Pais \& Filhos elege as atividades corporais e esportivas como promotoras desses atributos. Goellner (2004, p. 364) destaca que, como

(...) espaço pedagógico, há muito o esporte tem sido campo privilegiado do exercício simbólico da virilidade e da construção de valores a ela agregados, visto que, culturalmente, foi e algumas vezes ainda é representado como sendo um espaço masculino. Agressividade, competitividade, risco, potência, vigor físico, velocidade e determinação são atributos associados ao masculino, em oposição à fragilidade, delicadeza, beleza física e flexibilidade, tidas como características femininas.

Esse estímulo da Pais \& Filhos para que as mulheres, mais especificamente as gestantes, adquiram vigor físico pode ser visto como um "atravessamento de fronteira", especialmente se considerarmos os padrões culturais na definição daquilo que é esperado para cada gênero, como observou Goellner (op. cit.).

Para Soares (2005, p. 52), as imagens esportivas jogam com certa concepção do esportista forte, que "é quase sempre movido pela ideia de ir mais longe, ser mais veloz, fazer a ultrapassagem dos limites das próprias forças, de regular os esforços (...), de superação de si mesmo". Parece que o estímulo à adoção das práticas esportivas dado pela publicação, a partir de 1980, culmina em 1990, com a adesão das mulheres à cultura da superação de limites, despertando seus desejos de vitória em diversos âmbitos da vida, inclusive na gestação. As práticas esportivas (como 
Mãe moderna: esportiva e forte

os campeonatos e as Olimpíadas) ajudaram a problematizar o mito do sexo frágil e alteraram outros tabus. Por exemplo, nos anos de 1980, Isabel, jogadora de voleibol de alto rendimento da seleção brasileira, provou que a gravidez não era empecilho, ao continuar atuando nas quadras durante todos os nove meses da gestação. A partir de então, a revista tem destacado cada vez mais a ampliação do número de mulheres envolvidas nos esportes de alto rendimento no Brasil e em práticas antes consideradas violentas. Nesse sentido, o território esportivo parece ser, como destaca Goellner (2004, p. 367), um território

(...) permeado por ambiguidades, o mundo esportivo fascina e desassossega homens e mulheres, tanto porque contesta os discursos legitimadores dos limites e condutas próprias de cada sexo, como porque, por meio de seus rituais, fazia vibrar a tensão entre liberação e controle de emoções, e também representações de masculinidade e feminilidade.

A experiência do corpo grávido e da vivência da gestação é sempre modificada pela cultura e, nessa direção, tomo as palavras de Antonin Artaud (2001, p. 43) para encerrar este artigo, quando ela diz: "Meu corpo é às vezes meu, uma vez que ele porta os traços de uma história que me é própria, de uma sensibilidade que é minha, mas ele contém, também, uma dimensão que me escapa radicalmente e que o reenvia ao simbolismo de minha sociedade”.

\section{Notas}

1. Menciono o nome e sobrenome do/a autor/a quando este/a é citado/a pela primeira vez no texto propriamente dito para visibilizar mulheres e homens a quem me refiro, assim como a grafia ola de algumas palavras.

2. As mães são estimuladas a registrar por escrito o crescimento do seu bebê, o peso, a estatura e a frequência das mamadas.

3. Não tenho dúvida de que os inúmeros cuidados corporais trouxeram efeitos positivos e abriram novas possibilidades para se viver a gestação.

4. A Pais \& Filhos foi publicada pela Editora Bloch; atualmente, é a Manchete que a edita. A escolha por essa revista deve-se, primeiramente, ao fato de ela ser uma publicação midiática de ampla circulação no Brasil, reconhecidamente privilegiada por seu tempo de permanência no mercado, se comparada a outras publicaçôes destinadas ao mesmo segmento. Ela surgiu em setembro de 1968 e mantém-se até hoje no mercado brasileiro, sendo, portanto, a mais antiga nesse gênero.

5. Estas evidências vão da inserção das mulheres nos clubes esportivos, passando pelo crescente número de competiçôes específicas para mulheres até a participação feminina brasileira em 
Jogos Olímpicos, que se iniciou em 1932 com a participação solitária de Maria Lenk na natação, e que em 1936, em Berlim, já havia crescido para seis competidoras. Para Schpun (1999, p. 122), os Jogos Femininos do Estado de São Paulo demonstraram, na década de 1930, que era ainda uma prática mais aceita e frequente entre jovens e mulheres das famílias de origem europeia, especialmente alemã.

6. O uso da expressão saúde é retomado porque, como observa Soares, se analisarmos o processo histórico da educação física no Brasil, perceberemos que esse tipo de legitimação das práticas corporais é bastante antigo. Soares (1994) afirma que as primeiras tentativas de incluir a educação física no universo escolar foram em nome da promoção da saúde, higiene física e mental, da educação moral e eugênica. A autora acrescenta que o sentido do conceito de saúde não ficou estático, modificando-se de acordo com as condiçōes históricas de possibilidades.

7. A ampliação da participação das mulheres nos esportes escolares foi autorizada pelo Conselho Nacional de Desportos (Brasil, 1979, 1983) e endossada por muitos acontecimentos e estudos científicos, que jogavam por terra os argumentos sobre a probabilidade de as mulheres estarem mais propensas às lesões esportivas do que os homens (Azevedo, 1988).

\section{Referências}

ARTAUD, A. Oevres. In: ARTAUD, A. Van Gogh: o suicidado da sociedade. Trad. Ferreira Goulard. Rio de Janeiro: José Olympio, 1993.

AZEVEDO, T.M.C. A mulher na Educação Física. 1988. Dissertação (mestrado em Educação) - Faculdade de Educação da UFE, Niterói.

BADINTER, Elisabeth. Hombres/mujeres: como salir del camino equivocado. Buenos Aires: Fondo de Cultura Económica, 2003.

BAUMAN, Z. O mal estar da pós-modernidade. Rio de Janeiro: Zahar, 1998.

BAUMAN, Z. Modernidade líquida. Rio de Janeiro: Zahar, 2000.

BAUMAN, Z. Amor líquido: sobre a fragilidade dos laços humanos. Rio de Janeiro: Zahar, 2003.

BEAUVOIR, S. O segundo sexo. Rio de Janeiro: Nova Fronteira, 1980.

BOLTANSKI, L. As classes sociais e o corpo. Rio de Janeiro: Edições Gral, 1979.

DAOILO, J. A cultura do corpo. São Paulo: Papirus, 2004.

DELEUZE, G. Foucault. São Paulo: Brasiliense, 2005. 
FISCHER, R.M.B. Problematizações sobre o exercício de ver: mídia e pesquisa em educação. Revista Brasileira de Educação, Campinas, n. 20, p. 40-65, maio/ago. 2002.

FORNA, A. Mãe de todos os mitos: como a sociedade modela e reprime as mães. Rio de Janeiro: Ediouro, 1999.

FOUCAULT, M. A ética do cuidado de si como prática da liberdade. In: FOUCAULT, M. Ética, sexualidade, política: ditos e escritos. v. 5. Rio de Janeiro: Forense Universitária: 1999.

HAYS, S. Contradições culturais da maternidade. Rio de Janeiro: Gryphus, 1998.

GOELLNER, S.V. O esporte e a espetacularização dos corpos femininos. Revista Labrys: Estudos Feministas, Brasília, DF, n. 4, p. 243-245 ago.-dez. 2003.

GOELLNER, S.V. Mulher e esporte no Brasil: fragmento de uma história generificada. In: SIMÕES, A.C.; KNIJNIK, J.D. (Org.). O mundo psicossocial da mulher no esporte: comportamento, gênero, desempenho. São Paulo: Aleph, 2004.

MEYER, D.E. As mamas como constituintes da maternidade: uma história do passado? Educação \& Realidade, Porto Alegre, v. 25, n. 2, p.113-126, jul.-dez. 2000.

MEYER, D.E. A politização contemporânea da modernidade. Gênero: Núcleo Transdisciplinar de Estudos de Gênero, Niterói, v. 6, n. 1, p. 120, 2006.

LOURO, G.L. Gênero, sexualidade e educação: uma perspectiva pós-estruturalista. Petrópolis: Vozes, 1999.

MARTINS, A.P.V. Visóes do feminino: a medicina da mulher no século XIX. Rio de Janeiro: Fiocruz, 2004.

PAIS \& FILHOS, São Paulo, v. 1-37. (Coleção).

PAIS \& FILHOS, São Paulo, n. 2, out. 1968. 
PAIS \& FILHOS, São Paulo, n. 28, dez. 1970.

PAIS \& FILHOS, São Paulo, n. 63, jan. 1974.

PAIS \& FILHOS, São Paulo, n. 110, dez. 1978.

PAIS \& FILHOS, São Paulo, n. 133, jan. 1980.

PAIS \& FILHOS, São Paulo, n. 233, fev. 1988.

PAIS \& FILHOS, São Paulo, n. 253, jan. 1990.

PAIS \& FILHOS, São Paulo, n. 434, maio 2004.

SABINO, C. O peso da forma: cotidiano e uso de drogas entre fisiculturistas. 2004. Tese (doutorado em Sociologia e Antropologia) - Instituto de Filosofia e Ciências Sociais da Universidade Federal do Rio de Janeiro, Rio de Janeiro.

SANT'ANNA, D.B. Educação física e história. In: CARVALHO, Y. Educação física e ciências humanas. São Paulo: Hucitec, 1997.

SCHPUN, M.R. Beleza em jogo: cultura física e comportamento em São Paulo nos anos 20. São Paulo: Editora Senac, 1999.

SOARES, C. Imagens da educação no corpo: estudo a partir da ginástica francesa no Século XIX. Campinas: Autores Associados, 2002.

SOARES, C. Arquitetura e educação do corpo: notas indicadas. Revista do Núcleo de Desenvolvimento da Criatividade da Unicamp, Campinas, v. 10, n. 1, p. 110-135, 2003.

SOARES, C. Cultura de movimento. Revista do Sesc: Corpo, prazer e movimento, São Paulo, v. 1, p. 14-23, 2003 a.

SOARES, C. Pedagogias do corpo. Revista Labrys: Estudos Feministas, Brasília, DF, n. 4, ago.-dez. 2003.

SOARES, C. Pedagogias do corpo: higiene, ginástica, esporte. In: RAGO, M.; VEIGA NETO, A. (Org.). Figuras de Foucault. Belo Horizonte: Autêntica, 2006. 
Mãe moderna: esportiva e forte

VIGARELLO, G.; SANT’ANNA, D. (Entrevista). O corpo inscrito na História: imagens de um arquivo vivo. Projeto História, São Paulo, n. 21 , p. 40-49, 2001.

Recebido em 5 de abril de 2011.

Aprovado em 30 de junho de 2012. 